\title{
Sensory analysis and mid-infrared spectroscopy for discriminating roasted specialty coffees
}

\author{
Danieli Grancieri Debona1 (iD), Emanuele Catarina da Silva Oliveira1 (iD), Carla Schwengber ten Caten² (D), \\ Rogério Carvalho Guarçoni ${ }^{3}$ (D), Taís Rizzo Moreira ${ }^{4}$ (D) Lucas Louzada Pereira $^{1}$ (D) , Aldemar Polonini Moreli ${ }^{1}$ (D)
}

\author{
${ }^{1}$ Instituto Federal do Espírito Santo/IFES, Venda Nova do Imigrante, ES, Brasil \\ ${ }^{2}$ Universidade Federal do Rio Grande do Sul/UFRGS, Porto Alegre, RS, Brasil \\ ${ }^{3}$ Instituto Capixaba de Pesquisa, Assistência Técnica e Extensão Rural/INCAPER, Vitória, ES, Brasil \\ ${ }^{4}$ Universidade Federal do Espírito Santo/UFES, Jerônimo Monteiro, ES, Brasil \\ Contact authors: danielidebona@hotmail.com; emanuele.oliveira@ifes.edu.br; tencaten@producao.ufrgs.br; rogerio.guarconi@incaper.es.gov.br; taisr.moreira@hotmail.com; \\ lucas.pereira@ifes.edu.br \\ Received in February 23, 2021 and approved in June 16, 2021
}

\section{ABSTRACT}

In general, the process of roasting coffee uses a rotated fix drum or fluidized bed. Theoretically, the fluidized bed can provide more homogenous roastings throughout the process. Thus, in this study, we analyzed the sensorial and chemical attributes for two different coffees submitted to three roasting profiles using fluidized bed roaster. The coffees were roasted for a high temperature for a short time (HTST), medium temperature for a medium time (MTMT), and low temperature for a long time (LTLT). Sensory analysis was performed on the roasted coffees according to the SCA methodology and chemical analysis through mid-infrared spectroscopy. The results of sensory analysis indicated a preference for MTMT roasting for coffee grown at high altitude and HTST roasting for coffee grown at low altitude. Chemically, coffees show that LTLT and MTMT roasts are most distant from each other in their chemical composition when roasting low altitude coffee, whereas the HTST and MTMT roasts are the most distant from each other when roasting high altitude coffee.

Key words: Arabica coffee; Coffee roasting; Infrared spectroscopy; Specialty coffee.

\section{INTRODUTION}

Coffee is the second most consumed beverage in the world, creating a complex production chain that plays a fundamental role in the economy, with effects on both producer countries and consumers (Ferreira; Santos, 2019; Giacalone et al., 2019).

Efforts to find processes that optimize the quality of this product have increased; however, the final product will result from a large number of factors, such as cultural, agronomic, chemical, and microbiological aspects (Pimenta; Angélico; Chalfoun, 2018). Coffee quality is also affected by elevation, that is, the higher the altitude of the coffee field, the better the edaphic and climatic conditions for the production of specialty coffees (Pereira et al., 2020; Worku et al., 2018).

Several processes are applied from the production phase to final consumption, and one of the most complex is roasting, in which the coffee bean is exposed to heat that induces chemical reactions, culminating in changes in the physical and chemical structure of the bean, making it suitable for beverage extraction (Schenker; Rothgeb, 2017).

On one hand, the point of view of processing, the roasting should be conducted to highlight coffee quality; therefore, knowing the interaction of the temperature to which beans are exposed and the duration of the exposure is fundamental since this binomial conducts the roasting process (Pramudita et al., 2017). On the other hand, there are several manners of combining roasting time and temperature, including high temperature at short time (HTST), medium temperature at medium time (MTMT), and low temperature at long time (LTLT) (Gloess et al., 2014; Putra; Hanifah; Karim, 2019).

The roasting process is divided into stages: dehydration, which is characterized by reduction in water content (Gloess et al., 2014); roasting more precisely, where Maillard reactions, caramelization, and pyrolysis occur (Pramudita et al., 2017); and cooling. How these stages are conducted determines the final formation of aroma and flavor compounds of coffee.

In each of these stages, different chemical compounds are formed, which are responsible for the sensory attributes that define the quality of the coffee. These attributes are identified and quantified by Q-Graders ${ }^{1}$ using sensory analysis. However, this methodology has been questioned, since small variations in the roasting process affect coffee in different ways, creating challenges for accurate analysis (Baqueta; Coqueiro; Valderrama, 2019; Craig et al., 2018).

The use of low-cost instrumental and qualitative methods in association with sensory analysis would be advantageous to reliably assess the beverage quality of coffee bean samples. Fast techniques, such as mid-infrared spectroscopy (Craig et al., 2018), can be useful for understanding phenomena that control coffee quality (Baqueta; Coqueiro; Valderrama, 2019). Infrared spectroscopy- MIR, has been used to analyze

${ }^{1} \mathrm{Q}$ Grader: Q-Graders are qualified, controlled and professionally trained coffee tasters from the Coffee Quality Institute (CQI). 
the quality of fermented coffees (Oliveira et al., 2020), to detect coffee adulteration (Tavares et al., 2012) and to classify roasted coffees regarding quality (Craig et al., 2018). Infrared spectroscopy has proven to be a viable technique for discrimination of roasting profiles for different coffees for the purpose of correlating them with sensory results.

Near-infrared spectroscopy and mid-infrared spectroscopy have been used in studies to identify coffee varieties, coffee origin, and coffee blends (Zhang et al., 2016). These techniques are analytically advantageous; and has been used in many fields, being suitable for coffee roasting industries, particularly in control of the roasting process. Advantages of this approach are fast response in analysis and reduced or even unnecessary preparation of samples, considering either green coffee or roasted coffee (Santos et al., 2016).

Therefore, three roasting profiles are used in this study - HTST (high temperature at short time), MTMT(medium temperature at medium time), and LTLT(low temperature at long time) - on coffees grown at different altitudes to determine if the application of different roasting profiles, with different time and temperature gradients, modify the sensory and chemical structure of the coffees. An additional question is whether altitude is a factor that affects the roasting process, that is, whether coffees from different altitude ranges respond better to certain roasting profiles.

We present two panels in this study: the first is the sensory analysis performed by Q-graders, and the second is the analysis of medium infrared (MID) spectroscopy of the roasted grains to identify and separate the classes of chemical compounds that have formed as a result of the roasting routines applied, and this separation was performed using PCA (multivariate main component analysis) which is an exploratory analysis technique, successfully applied for spectral data analysis (Baqueta et al, 2021a; Baqueta et al, 2021b; Oliveira et al., 2020).

\section{MATERIAL AND METHODS}

\subsection{Raw materials}

The arabica coffee (Coffee arabica L.) used for the experiment came from two properties in the state of Espírito Santo - Brazil that have a history of growing specialty coffees, one at 750 meters (low altitude) at $20^{\circ} 31^{\prime} 35.5^{\prime} \mathrm{S}$, $40^{\circ} 45^{\prime} 14.0^{\prime \prime} \mathrm{W}$ and the other at 1050 meters (high altitude) at $20^{\circ} 20^{\prime} 12$ 'S, $41^{\circ} 05^{\prime} 43^{\prime \prime} \mathrm{W}$.

The coffee fruit was collected at $85 \%$ maturity in 2018 and was processed at the Coffee Analysis and Research Laboratory (Laboratório de Análise e Pesquisaem Café LAPC) of the Federal Institute of Espírito Santo (IFES), where the mature, green, and floater beans were cleaned and separated. The mature fruit was pulped with a Pinhalense sample pulper.
Semi-dry processing was adopted for both coffee samples. This process has been applied in regions of higher altitude with high moisture to avoid undesirable spontaneous fermentation; the procedures followed the recommendations of Pereira et al. (2020). The coffee beans were then dried on a suspended terrace until reaching $12 \%$ moisture content to maintain quality.

After the coffee was dried, it was classified physically, and only beans free of defects in the 16 \# UP sieve were used for the roasting procedures, according to the SCA methodology (Specialty Coffee Association of America - SCAA, 2008).

\subsection{Roasting profiles}

Three roasting profiles were defined based on variations of time and temperature: high temperature at short time (HTST), medium temperature at medium time (MTMT), and low temperature at long time (LTLT). These processes were adapted from the studies of Gloess et al. (2014), Schenker and Rothgeb (2017) and Wang and Lim (2014).

The HTST roasting profile started at $180{ }^{\circ} \mathrm{C}$, roasting time was 6 minutes and 30 seconds, and the final temperature was $210{ }^{\circ} \mathrm{C}$. The MTMT roasting profile started at $140{ }^{\circ} \mathrm{C}$ roasting time was 8 minutes, and the final temperature was $210^{\circ} \mathrm{C}$. The LTLT roasting profile started at $120^{\circ} \mathrm{C}$, roasting time was 10 minutes, and the final temperature was $210^{\circ} \mathrm{C}$.

Information in the literature regarding the variation of the temperature gradient per minute and the development of the roasts was used to define the roasting profiles, which is given by the time between the " $\operatorname{crack}^{2}$ " temperature threshold and removal of the coffee from the roaster, according to Giacalone et al. (2019) and Yang et al. (2016).

A visual representation of the roasting profiles that indicate the roasting conditions with the time-temperature variation is shown in Figure 1.

\footnotetext{
${ }^{2}$ It is a popping sound, resulting from the rupture of the cell walls of the coffee bean subjected to high internal pressure due to high temperatures.
}

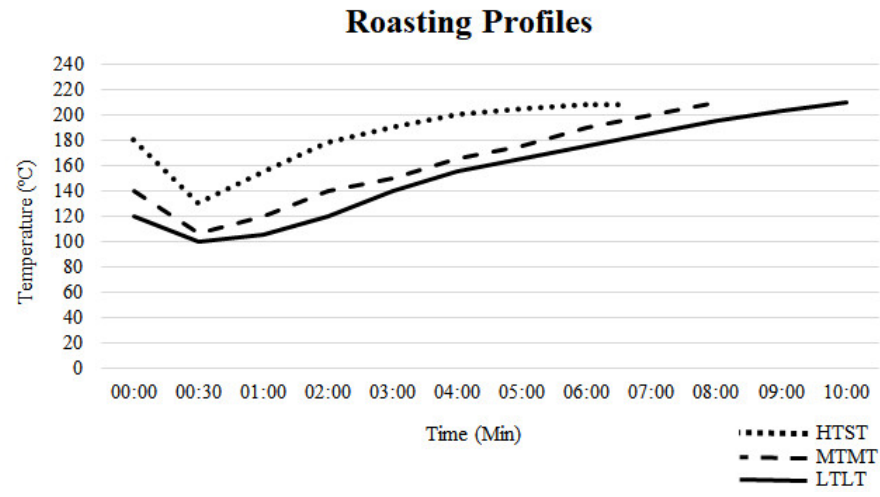

Figure 1: Roasting profiles: HTST - high temperature at short time, MTMT - medium temperature at medium time and LTLT - low temperature at long time, with binomial variation, time and temperature. 


\subsection{Coffee roasting procedures}

The roasting was carried out in the automated IKAWA PRO, a fluidized bed sample roaster, which allows consistent and repeatable roasting with digital precision (IKAWA, 2020).

Each sample for roasting consisted of $50 \mathrm{~g}$ of green coffee, the maximum capacity of the roaster. The roasting curves were programmed and set up on the equipment so the temperature of the roaster increased as defined, maintaining the desired stability and consistency for the present experiment.

An automation feature of the roaster allows the coffee to be removed with no chaff and already cooled at the end of each roast. The samples were then stored in silver-color metalized film polyester packages, with $250 \mathrm{~g}$ capacity. Two storage packages were used for each sample; the first was placed in an environment with a temperature of up to $25^{\circ} \mathrm{C}$, to later be used in sensory analysis, and the second was placed in an environment with temperature of $-22{ }^{\circ} \mathrm{C}$ for chemical analysis (Gloess et al., 2014).

\subsection{Sensory analysis according to specialty coffee association protocol}

Sensory analysis was performed according to the guidelines of the Specialty Coffee Association (SCA). The samples were roasted 24 hours before sensory analysis; at 12 hours after roasting, the coffees were ground in a disc mill, Bunn Coffee Mill, model G3A HD, to particle size such that from $70 \%$ to $75 \%$ of the particles passed through a US Standard 20 mesh sieve. The ground coffee samples were placed in 5 cups containing $8,25 \mathrm{~g}$ of coffee and $150 \mathrm{ml}$ of mineral water at $93{ }^{\circ} \mathrm{C}$. The coffees were evaluated at the Coffee Analysis and Research Laboratory (LAPC) by five Q-Graders, using the SCA 2020 protocol.

The SCA protocol considers eleven attributes: Fragrance/Aroma, Uniformity, Clean cup, Sweetness, Flavor, Acidity, Body, Aftertaste, Balance, Overall, and Defects. The evaluation is expressed on a centesimal numerical scale (SCAA, 2008). In the end, a score is calculated that will define the quality of the coffee. Scores from 80 to 100 indicate specialty coffee with increasing quality. A score below 80 indicates non-specialty coffee.

\subsection{Mid-infrared spectroscopy analyses}

For mid-infrared analysis, the coffee samples were ground in a Bunn Coffee Mill, model G3A HD, to particle size such that from $70 \%$ to $75 \%$ of the particles pass through a $0.074 \mathrm{~mm}$ mesh sieve, according to US standards. For each sample, four tablets were made, each tablet contained $3 \mathrm{~g}$ of ground coffee formed in a manual press without adding $\mathrm{KBr}$ (Tavares et al., 2012).
To obtain the spectra, the tablets were placed on the ATR (attenuated total reflectance) crystal in the Cary 630 FTIR Spectrometer infrared equipment, manufactured by Agilent Technologies, using an ATR diamond accessory with a $45^{\circ}$ reflection angle, $0.001 \mathrm{~m}$ in diameter, active area of $200 \mu \mathrm{m}$, and penetration of approximately $2 \mu \mathrm{m}$ depth in the sample. The spectral region was from 40 to $6.5 \mathrm{~m}^{-1}$ with an average of 8 scans with $0.04 \mathrm{~m}^{-1}$ resolution. This spectral region is considered to reveal a large amount of information that can be used for functional characterization of organic compounds (Pavia et al., 2014; Silverstein; Webster; Kiemle, 2005).

\subsection{Statistical data analysis}

The experiment was conducted in a completely randomized design with five replications in a $2 \times 3$ factorial arrangement, composed of coffees produced at two altitudes, 750 and 1050 meters, under three roasting profiles, HTST, MTMT, and LTLT, totaling 30 samples.

For statistical analyses of the sensory results, the $R$ Core program was used. The sensory results were analyzed to check for differences between sensory attributes in the beverages of coffee beans in the three roasting profiles of coffees grown at the two altitudes, followed by evaluation of consistency in sensory perception among Q-Graders. Combined analysis of experiments was used for that purpose, with the means compared by Tukey's test at the 5\% significance level. In evaluation of the similarity in scoring between Q-Graders, a matrix was elaborated with the means of the variables and, subsequently, dendrograms were constructed using the Average Euclidean distance to measure the distances between the Q-Graders and the complete linkage hierarchical clustering method.

The original spectra were organized in a matrix, where each replicate was considered a sample. All calculations were performed using Matlab software version 13a, $R$ Core Team, and Microsoft Excel version 2016. The data were centered on the mean and, subsequently, exploratory analysis was performed using the multivariate principal component analysis (PCA) technique to detect similarities and differences between coffees under the three roasting profiles.

\section{RESULTS}

\subsection{Sensory analysis}

The results of the sensory panel are shown in Table 1 and Figures 2 and 3.

Dendrograms for coffee grown at 750 meters (Figure 2) and at 1050meters (Figure 3) are shown for (A) HTST, (B) MTMT, and (C) LTLT roasting. 
Table 1: Average of the Final Score of attributes evaluated in three different roasting profiles of arabica coffee grown at two different altitudes, 750 and 1050meters.

\begin{tabular}{cccccccccc}
\hline \multirow{2}{*}{ Roasting } & \multicolumn{9}{c}{ Altitude } \\
\cline { 2 - 9 } & \multicolumn{7}{c}{750 meters } & \multicolumn{1}{c}{1050 meters } & Average \\
\hline HTST & 78.82 & a & B & 86.23 & a & A & 82.53 & a \\
MTMT & 77.81 & a & B & 86.62 & a & A & 82.22 & a \\
LTLT & 78.84 & a & B & 85.37 & a & A & 82.11 & a \\
Average & 78.49 & & & 86.07 & & & & \\
\hline
\end{tabular}

${ }^{1}$ Averages followed by at least one identical lowercase letter in the column and at least one identical uppercase letter in the row do not differ by Tukey's test at $5 \%$ probability.

\subsection{Mid-infrared data analysis}

The PCA method was applied, generating a distribution of the samples based on the roasting profiles applied to each of the coffees. Figure 4 presents two diagrams: (A) scores and (B) loadings for coffee grown at the altitude of 750 meters; Figure 5 presents the data for coffee grown at the altitude of 1050 meters.

\section{DISCUSSION}

\subsection{Sensory analysis}

According to Table 1 , there is no statistical difference $(\mathrm{p}>$ 0.05) between the roasting profiles HTST, MTMT, and LTLT for both coffees, which shows that when using the same sieve mesh (16 \#UP) specifically for the presented roasting profiles, there is no difference in sensory perception when using the fluidized bed roasting system. This suggests, then, that studies with separations of sieves and applications of the same roasting routines should be carried out under the same conditions, aiming at a better understanding of these interactions.

However, there is a difference between the 750meters and 1050meters coffees. This difference can be attributed to terroir, since coffee is a product that has its value stipulated according to quality, which depends on the characteristics of the place where it is produced. Coffees of different topographical origin have different sensory scores and quality levels, confirming the results of Conley and Wilson (2020) and Joët et al. (2010).

Concerning sensory attributes of fragrance, flavor, aftertaste, acidity, and body show no significant difference ( $p>0.05$ ) for the roasting profiles; however, the mean values of these attributes are higher for coffee grown at 1050meters, reaffirming that altitude positively affects final beverage quality, in agreement with results of Martins et al. (2020).

In considering all the Q-Graders that evaluated the coffees, dendrograms (A) and (B) of Figure 2 suggest the existence of three homogeneous groups: the first group formed by Q-Graders 1, 2, and 4; the second by cupper 3; and the last by cupper 5 . Dendrogram (C) suggests the existence of three groups: the first formed by Q-Graders 1 and 2, the second by 3 , and the last by 4 and 5 .
(A)

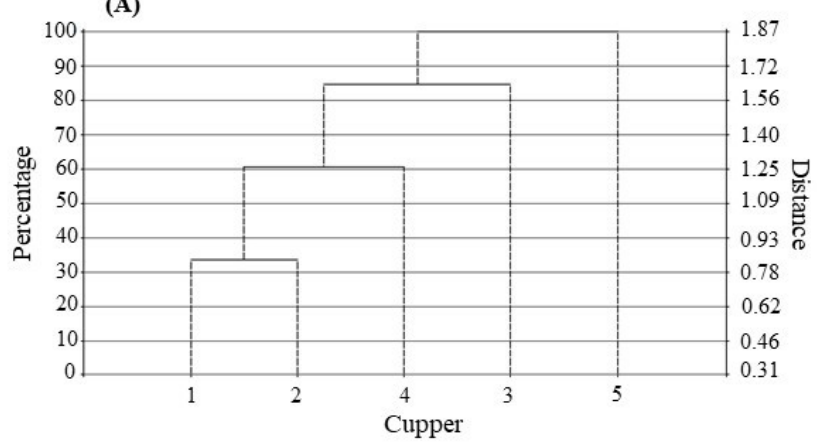

(B)

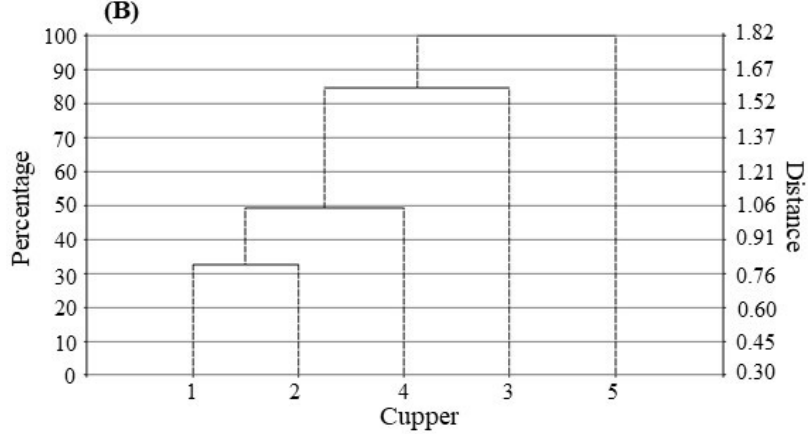

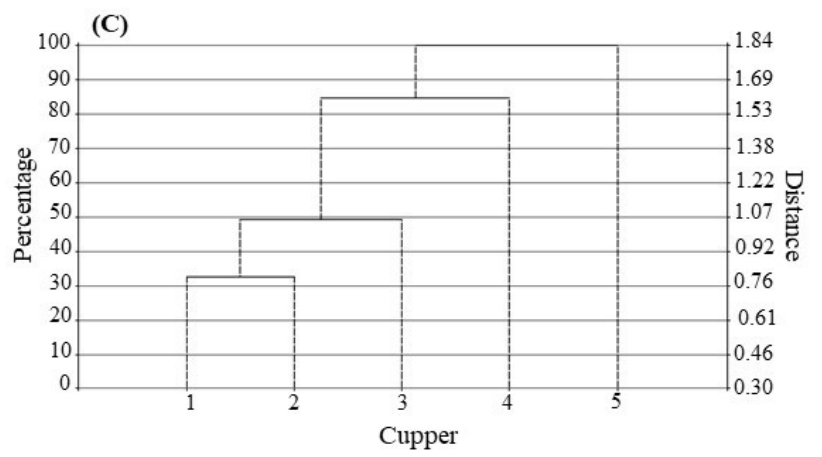

Figure 2: Dendrograms obtained from results of evaluations of 5 Q-Graders of coffee from the altitude of 750 meters under HTST roasting $(A)$, MTMT roasting $(B)$, and LTLT roasting $(C)$. 

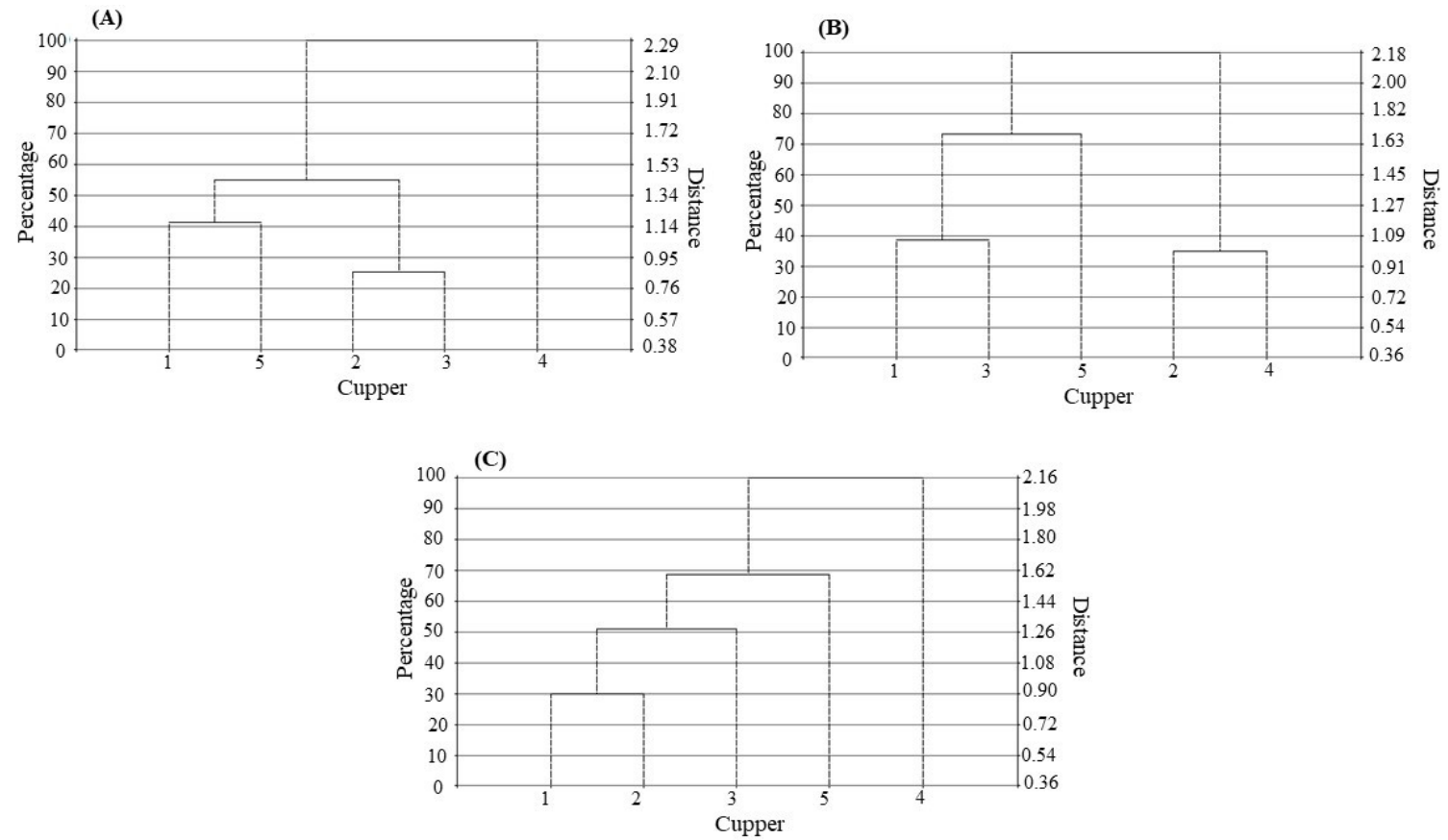

Figure 3: Dendrograms obtained from results of evaluations of 5 Q-Graders of coffee from the altitude of 1050 meters under HTST roasting $(A)$, MTMT roasting $(B)$, and LTLT roasting $(C)$.
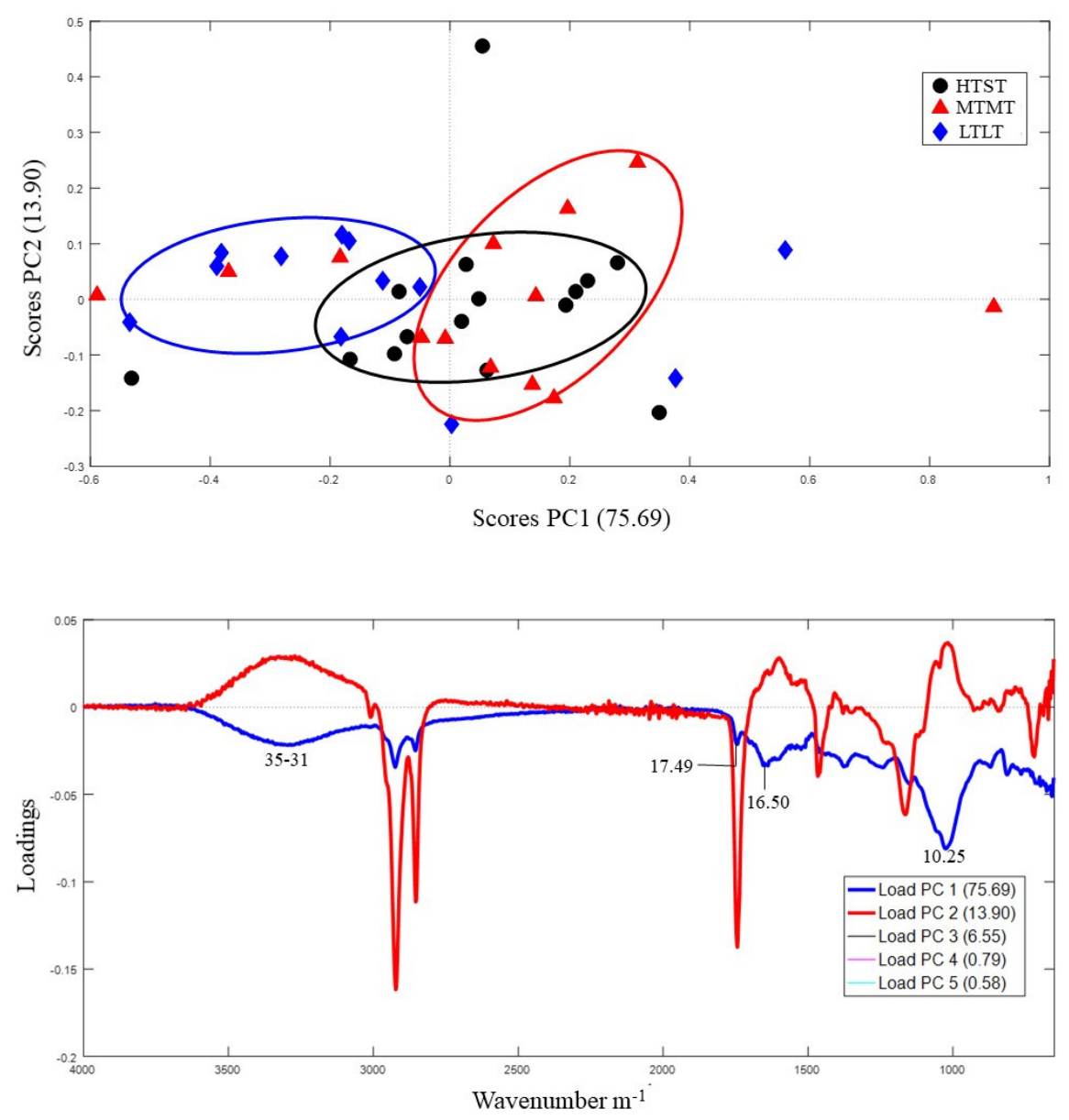

Figure 4: Scores (A) and Loadings (B) diagrams, referring to coffee grown at 750 meters altitude under three roasting profiles: HTST, high temperature at short time $(\bullet)$; MTMT, medium temperature at medium time $(\mathbf{\Delta})$; and LTLT, low temperatures at long time $(\diamond)$. 

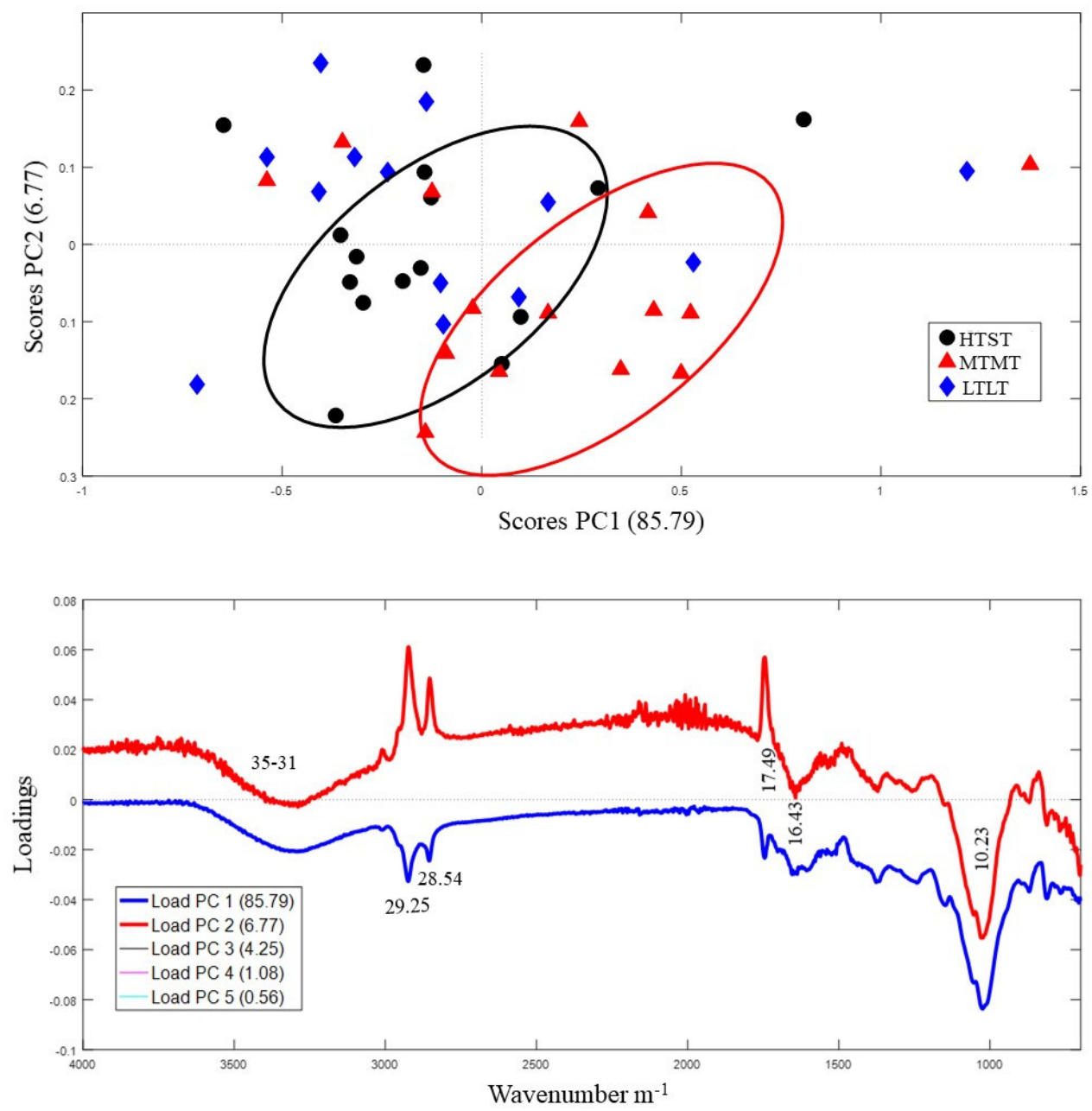

Figure 5: Scores $(A)$ and Loadings $(B)$ diagrams, referring to coffee grown at 1050 meters altitude under three roasting profiles: HTST, high temperature at short time $(\bullet)$; MTMT, medium temperature at medium time $(\boldsymbol{\Delta})$; and LTLT, low temperatures at long time $(\diamond)$.

The HTST (A) and MTMT (B) roasting profiles show Q-Graders 3 and 5 had different sensory perceptions from the others. However, when LTLT roasting is considered, cupper 3 is in a dissimilar position, but cupper 5 had sensory perception similar to cupper 4 , showing that the type of roasting procedure affects the perception of SCA attributes for low-altitude coffees.

Differences between the sensory perception of Q-Graders is a recurring phenomenon, initially discussed by Pereira et al. (2017) and expanded by Pereira et al. (2019). For these authors, the variations between the grouping of Q-Grades, indicate a high sensitivity of them in the judgment of a coffee, which reflects in the individual perception and often different from the evaluators in relation to a coffee. Thus, complementary techniques must be considered in studies of calibration and verification of adulteration of products to reinforce the sensorial understanding at the expense of the chemical matrix of a product, aiming at greater precision of industrial processes.

Based on this and the dendrograms (Figure 2), the HTST roast shows the respective weights of the variables in construction of the multivariate models; flavor indicating $30 \%$ and aftertaste indicating $20 \%$ are the variables that contributed most to such results, corroborating the studies of Putra, Hanifah and Karim, (2019), who claim that fast roasting produces coffee with a more pleasant flavor. Flavor is the main characteristic of coffee, as it reflects the intensity, quality, and complexity of the taste and aroma combination.

As the MTMT is a roasting profile intermediate between HTST and LTLT, the body (40\%) and flavor (20\%) variables most contribute to your multivariate model. In this case, the intense body of the coffee beverage has been attenuated under the roasting conditions, which accumulates to the ideal degree of roasting (Schenker; Rothgeb, 2017).

Finally, for the LTLT roast, the overall variable contributed $30 \%$ and aftertaste $30 \%$ to the multivariate model. Aftertaste is characterized by the persistence of flavor on the palate, which may be pleasant or not. As the roasting profile is long, the aftertaste becomes intense and bitter, due to degradation of acids, which is a consequence of long exposure to the heat of roasting (Giacalone et al., 2019). 
Therefore, for low altitude coffee, the best roasting profile perceived by the Q-Graders is the HTST profile, followed by the MTMT and LTLT profiles.

Data for coffee grown at higher altitude is shown in dendrogram (A) of Figure 3, suggesting the existence of two homogeneous groups: the first formed by Q-Grader 4 and the second by the others. Dendrogram (B) suggests the existence of three distinct groups: the first formed by Q-Graders 1 and 3, the second formed by Q-Grader 5, and the third by Q-Graders 2 and 4. Finally, dendrogram (C) suggests the existence of two homogeneous groups: the first group formed by cupper 4 and the second by the others.

For coffees grown at higher altitude, the Q-Graders modify their scores according to variation in the roasting profile. Q-Grader 4 had different sensory perceptions than the others for the HTST and LTLT roasts, whereas for the MTMT roast, the same Q-Grader 4 had perceptions similar to Q-Grader 2 and perceptions dissimilar to Q-Graders 1 and 3 , who had perceptions similar to each other, contributing the results of Pereira et al. (2020) which says that coffees from higher-altitude areas have sensory notes more exotic observations for quality, which are highlighted differently by the roasting profiles, due to the formation of different chemical compounds (Bodner et al., 2019).

The attributes that corroborated for construction of the dendrograms (Figure 3) were acidity $(50 \%)$, aftertaste $(30 \%)$, fragrance $(10 \%)$, and overall $(10 \%)$ for the MTMT roast; and acidity $(50 \%)$, aftertaste $(30 \%)$, and overall $(20 \%)$ for LTLT. For the HTST roasting profile, the variables of acidity $(40 \%)$, aftertaste $(30 \%)$, fragrance $(10 \%)$, and overall $(10 \%)$ contributed to construction of the models. Acidity was prominent in all the roasting profiles because the climatic conditions in which high-altitude coffee is grown favor the presence of this attribute. For high-altitude coffees, the roasting profile that received the best evaluation from Q-graders was MTMT, followed by HTST and LTLT.

These variations in the sensory panel indicate that the cupping technique with specialists of the Q-Grader was not sufficient to discriminate between coffees in relation to the roasting profiles used. The data presented in the sensory panel show that the Q-Graders did not perceive changes in the sensory profile according to the roasting curves within each set of samples. This suggests the need to expand analytical techniques for greater quality control in the industry.

\subsection{Mid-infrared data analysis}

Observing the score diagrams (Figure 4A), a subtle separation of the LTLT profile from the others is perceived along the first component. Thus, in the loading diagram (B) of Figure 4, it was possible to identify 4 regions of greatest importance in PC1, $35-31 \mathrm{~m}^{-1}$, related to axial deformation vibrations in hydrogen atoms bound to nitrogen, the origin of primary aliphatic and aromatic amines, or the $\mathrm{OH}$ bond present in sugars and carboxylic acids. The double $\mathrm{C}=\mathrm{O}$ bonds of triglyceride give rise to the esters in the peak close to $17.49 \mathrm{~m}^{-1}$ (Zhang et al., 2016); lipids may also be present in this band. The peak at $16.50 \mathrm{~m}^{-1}$ indicates the presence of carbonyl from the amino acid carboxylate. The $10.25 \mathrm{~m}^{-1}$ region shows the presence of the $\mathrm{C}-\mathrm{O}$ bond, which may refer to sugars or carboxylic acids. Both compounds are constituents of the complex Maillard reaction chain, combining to develop flavor and aroma. (Poisson et al., 2017).

The LTLT roast, due to long exposure to low temperatures, has a lower degree of porosity (Schenker et al., 2000) and, consequently, lower $\mathrm{CO}_{2}$ degassing, showing a residual content of this gas according to the type of roast used. According to Wang and Lim (2014), this factor is related to the amount of moisture in the coffee bean, either in the case of roasting with an LTLT profile, or in accordance with the condition of oils presents throughout prolonged roasting, which are shown in diagram (B) of Figure 4 by the peak at $17,49 \mathrm{~m}^{-1}$.

Sensory analysis shows that flavor was the attribute that most contributed to the multivariate model for the HTST roast to coffee grown at 750 meters altitude (Figure 2). This attribute may be the result of the amine compounds that in the loading diagram (Figure 4B) are represented by the peak of $35-31 \mathrm{~m}^{-1}$. According to Kurniawan et al. (2017), these compounds may be a product of the Maillard reaction, which triggers the appearance of components such as pyridines during the roasting process that contribute to the formation of coffee flavor and aroma (Chin et al, 2011).

From a sensory perspective for the MTMT roasting profile of low altitude coffee, the body attribute most contributed to the multivariate model (Figure 2), which can be attributed to lipids $\left(17.49 \mathrm{~m}^{-1}\right)$, as shown in the (Figure 4B) (Zhang et al., 2016) since they increase the viscosity of coffee and reduce its density, improving the tactile sensation in the mouth (Esteban-Díez; González-Sáiz; Pizarro, 2004).

In diagram (A) of Figure 5, when observing the first component, it is understood that there is a tendency of separation between the HTST roast on the right and the MTMT roast on the left. Figure 5 diagram (B) shows 2 main bands in PC1, namely $29.27 \mathrm{~m}^{-1}$, which concerns the presence of compounds with an aliphatic $\mathrm{C}-\mathrm{H}$ bond, with carbon being primary or secondary, and the $28.54 \mathrm{~m}^{-1}$ point, which features aldehyde formed from lipids (Poisson et al., 2017).

There was no difference in the sensory variables that most affected the final scores of the cuppers for either roasting profile; however, chemically there is a tendency for structural changes in chemical compositions that may be related to the presence of organic alcohol compounds (29.25-29.27 $\mathrm{m}^{-1}$ ) (Moreira; Trugo; De Maria, 2000) oraliphatic esters andaldehyde $\left(28.54 \mathrm{~m}^{-1}\right)$ that are formed during the roasting process (Craig, 2018; Poisson et al., 2017). 
Finally, the results show that the use of the roasting profile in the fluidized bed roasting system, should be better understood in connection with coffee growing conditions and that the altitude/terroir factor was decisive for sensory perceptions of the Q-Graders.

\section{CONCLUSIONS}

The HTST roasting profile (high temperature for a short time) showed the best sensory result for arabica coffee grown at low altitude. As for coffee grown at high altitude, the MTMT roasting profile (medium temperature for medium time) had the best positive attributes for the Q-Graders. The LTLT roasting profile (low temperatures for a long time) received the worst evaluation from the Q-Graders for both coffees.

Mid-infrared spectroscopy was able to identify the classes of chemical compounds responsible for the separation of the roasting profiles for coffees grown at different altitudes, confirming that when the technique is used together with sensory analysis, it can effectively contribute to a better understanding of the chemical composition of the coffee beans favorable to higher coffee quality.

Other chemical analyses should be applied in future studies to better identify and quantify the chemical compounds that make up the roasted beans and determine how these compounds change according to the origin of the coffee and the roasting profile used.

\section{ACKNOWLEDGMENTS}

Free Admission Credit Cooperative - Sicoob (23186000886201801), the Coordination of Superior Level Staff Improvement - CAPES and National Council for Scientific and Technological Development - CNPq, the Federal Institute of Espírito Santo, for supporting the research, through the PRPPG $n^{\circ}$. 10/2019 - Productivity Researcher Program - PPP, the Institute Capixaba de Technical Assistance and Rural Extension - INCAPER. Finally, we thank the coffee producers, Newton Hoffman and DérioBrioschi, for donating the coffees to carry out the experiments.

\section{REFERENCES}

BAQUETA, M. R.; COQUEIRO, A.; VALDERRAMA, P. Brazilian coffee blends: A simple and fast method by near-infrared spectroscopy for the determination of the sensory attributes elicited in professional coffee cupping. Journal of food science, 84(6):1247-1255, 2019.

BAQUETA, M. R. et al. Multivariate classification for the direct determination of cup profile in coffee blends via handheld near-infrared spectroscopy. Talanta, 222:121526, 2021a.

BAQUETA, M. R. et al. Integrated 1H NMR fingerprint with NIR spectroscopy, sensory properties, and quality parameters in a multi-block data analysis using ComDim to evaluate coffee blends. Food Chemistry, 355:129618, 2021b.

BODNER, M. et al. Effect of harvesting altitude, fermentation time and roasting degree on the aroma released by coffee powder monitored by proton transfer reaction mass spectrometry. European Food Research and Technology, 245(7):1499-1506, 2019.

CHIN, S. T. Et al. Identification of potent odourants in wine and brewed coffee using gas chromatographyolfactometry and comprehensive two-dimensional gas chromatography. Journal of Chromatography A, 1218(42):7487-7498, 2011.

CONLEY, J.; WILSON, B. Coffee terroir: Cupping description profiles and their impact upon prices in Central American coffees. GeoJournal, 85:67-79, 2020.

CRAIG, A. P. et al. Mid infrared spectroscopy and chemometrics as tools for the classification of roasted coffees by cup quality. Food Chemistry, 245:1052-1061, 2018.

ESTEBAN-DÍEZ, I.; GONZÁLEZ-SÁIZ, J. M.; PIZARRO, C. Prediction of sensory properties of espresso from roasted coffee samples by near-infrared spectroscopy. Analytica Chimica Acta, 525(2):171-182, 2004.

FERREIRA, L. T.; SANTOS, J. Taxa de crescimento do consumo mundial de café de $2 \%$ ao ano projeta 208 milhões de sacas até 2030. EMBRAPA, 2019. Available in: <https://www.embrapa.br/busca-de-noticias/-/ noticia/44984677/taxa-de-crescimento-do-consumomundial-de-cafe-de-2-ao-ano-projeta-208-milhoes-desacas-ate-2030>. Access in: October 20, 2020.

GIACALONE, D. et al. Common roasting defects in coffee: Aroma composition, sensory characterization and consumer perception. Food Quality and Preference, 71:463-474, 2019.

GLOESS, A. N. et al. Evidence of different flavour formation dynamics by roasting coffee from different origins: Online analysis with PTR-ToF-MS. International Journal of Mass Spectrometry, 365:324-337, 2014.

IKAWA Coffee. For professionals. 2020. Available in: https://www.ikawacoffee.com/for-professionals. Access in: October 20, 2020. 
JOËT, T. et al. Influence of environmental factors, wet processing and their interactions on the biochemical composition of green Arabica coffee beans. Food chemistry, 118(3):693-701, 2010.

KURNIAWAN, M. F. et al. Metabolomic approach for understanding phenolic compounds and melanoidin roles on antioxidant activity of Indonesia robusta and arabica coffee extracts. Food science and biotechnology, 26(6):1475-1480, 2017.

MARTINS, P. M. M. et al. Coffee growing altitude influences the microbiota, chemical compounds and the quality of fermented coffees. Food Research International, 129:108872, 2020.

MOREIRA, R. F. A.; TRUGO, L. C.; DE MARIA, C. A. B. Componentes voláteis do café torrado. Parte II. Compostos alifáticos, alicíclicos e aromáticos. Química Nova, 23(2):195-203, 2000.

OLIVEIRA, E. C. S. da. et al. Espectroscopia de infravermelho para estudo de café conilon fermentado Infrared spectroscopy for the study of fermented conilon coffee. Brazilian Journal of Development, 6(4):1924819259, 2020.

PAVIA, D. L.; LAMPMAN, G. M.; KRIZ, G. S. Introduction to Spectroscopy. 3rd ed. Thomson Learning, Orlando, USA, 2014. 784p.

PEREIRA, L. L. et al. The consistency in the sensory analysis of coffees using Q-graders. European Food Research and Technology, 243(9):1545-1554, 2017.

PEREIRA, L. L. et al. Very beyond subjectivity: The limit of accuracy of Q-Graders. Journal of texture studies, 50(2):172-184, 2019.

PEREIRA, L. L. et al. New propositions about coffee wet processing: Chemical and sensory perspectives. Food Chemistry, 310:125943, 2020.

PIMENTA, C. J.; ANGÉLICO, C. L.; CHALFOUN, S. M. Challengs in coffee quality: Cultural, chemical and microbiological aspects. Ciência e Agrotecnologia, 42(4):337-349, 2018.

POISSON, L. et al. The chemistry of roasting-decoding flavor formation. In: FOLMER B. The Craft and Science of Coffee. London: Elsevier Science, 2017, p 273-309.
PRAMUDITA, D. et al. Roasting and colouring curves for coffee beans with broad time-temperature variations. Food and Bioprocess Technology, 10(8):1509-1520, 2017.

PUTRA, S. A.; HANIFAH, U.; KARIM, M. A. Theoretical study of fluidization and heat transfer on fluidized bed coffee roaster. AIP Conference Proceedings, 2097(1):17, 2019.

SANTOS, J. R. et al. Exploiting near infrared spectroscopy as an analytical tool for on-line monitoring of acidity during coffee roasting. Food Control, 60:408-415, 2016.

SPECIALTY COFFEE ASSOCIATION OF AMERICA SCAA. SCAA Cupping protocols. 2008. Available in: $<$ https://sca.coffee/research/protocols-best-practices $>$ Access in: June, 14, 2020.

SCHENKER, S. et al. Pore structure of coffee beans affected by roasting conditions. Journal of Food Science, 65(3):452-457, 2000.

SCHENKER, S.; ROTHGEB, T. The roast-creating the beans' signature. In: FOLMER, B. The craft and science of coffee. London: Elsevier Science. p. 245-271, 2017.

SILVERSTEIN, R. M.; WEBSTER, F. X.; KIEMLE, D. J. Spectrometric identification of organic compounds. New York: John Wiley \& Sons, 2005. 464p.

TAVARES, K. M. et al. Espectroscopia no infravermelho médio e análise sensorial aplicada à detecção de adulteração de café torrado por adição de cascas de café. Química Nova, 35(6):1164-1168, 2012.

WANG, X.; LIM, L. T. Effect of roasting conditions on carbon dioxide degassing behavior in coffee. Food research international, 61:144-151, 2014.

WORKU, M. et al. Effect of altitude on biochemical composition and quality of green arabica coffee beans can be affected by shade and postharvest processing method. Food Research International, 105:278-285, 2018.

YANG, N. et al. Determination of volatile marker compounds of common coffee roast defects. Food Chemistry, 211:206-214, 2016.

ZHANG, C. et al. Mid-Infrared spectroscopy for coffee variety identification: comparison of pattern recognition methods. Journal of Spectroscopy, 2016:7927286, 2016 